\title{
Customer Relationship Management in Online Grocery Stores
}

\section{Manpreet Kaur*}

Amity Business School, Amity University, India

\begin{abstract}
Purpose: This paper investigates into Customer Relationship Management activities done by Online Grocery Portals that leads to greater Customer satisfaction and how these activities play a major role in increasing value of the company.

Methodology: The Descriptive and Exploratory research design was used to conduct this research. Descriptive Research Design will be used for collection of primary data with the help of a structured questionnaire to assess the importance of CRM in online grocery shopping. The respondents were chosen from the National Capital Region of Delhi through Non-probability convenience Sampling with the help of a structured questionnaire.

Findings: Though all the Online Grocery stores are working tremendously on increasing Customer satisfaction from their services, they are still unable to meet the expectations of the customers in an efficient manner. As per our study of the factors taken in our research project we came to know that all the portals we have studied lack in some or the other field where they need to work with perseverance to get the adequate results and improve their competency.

Research limitations/implications: Due to lack of time and resources we were unable to conduct study on large number of online shoppers. The study is limited to only 206 people that is very less a number to implement this study to understand and view the psychology of the entire population.

Originality/value: This paper creates awareness about factors that have created customer satisfaction from the online portals studied in the research paper. It will also help the companies in understanding the loop holes that are responsible for customer satisfaction from the online grocery portals.
\end{abstract}

Keywords: Customer relationship management; Customer expectations; Customers satisfaction; Brand value; Online grocery stores; Brand loyalty

\section{Introduction}

The number of individuals and businesses buying groceries and grocery products online has increased to a large extent. The order is made through an e-commerce website and a mobile application, and the grocery store is delivered at a designated location in order to pay a small amount of freight for this service. Consumers evaluate the benefits and costs of this decision when deciding to purchase groceries. The next decision is to choose between a traditional physical store and a straight online grocery store. This decision is based on five important factors that determine whether consumers shop online or in physical stores and these

- Price

- Ambiance

- Convenience

- Service, and

- Product variety.

In order to capture the attention of consumers and gain a competitive advantage, physical stores are mainly concerned about prices and varieties. Due to the service costs incurred when shopping online, traditional stores gain an advantage in online stores by way of comparative pricing. However, electronic grocery stores are keeping pace with traditional stores in product categories. They are considered to have a competitive advantage, involving atmosphere, convenience and the other three dimensions of service.

\section{History of online grocery in world}

The foundation of online grocery stores was born in Britain in the
$1990 \mathrm{~s}$. This business model took about 20 years to become effective and efficient. Tesco began to explore the possibility that the Internet may be used to improve its core business scope and promote retail stores.

Therefore, Tesco proposed the idea of an incremental business model. They created a "super shop" for collecting online orders. Soon, they began selling groceries online, becoming the first big company to launch online services. Although Tesco hadn't gained any advantage from the pioneers at first, as long as the Internet bubble started to grow, Tesco gained a lot because of the clarity and experience of online transactions.

In the U.S., start-up companies that enter pure-line-based business models into grocery retail stores are active members. Among these start-ups, webvan and peapod have received a lot of attention due to their competitive technology and advanced promotion. The food business has been slowly rising and it has become a new source of income for start-ups around the world.

\section{Origin of online grocery business in India}

In 2011, some startups put forward the idea of purchasing online grocery in India. All of these startups are striving to create their own image and status in the online market in India. Unfortunately, almost everyone has failed, mainly because of a lack of customer base and investment. Only a few survived.

*Corresponding author: Manpreet Kaur, Amity Business School, Amity University, India, Tel: 9205516484; E-mail: manna130595@gmail.com

Received May 02, 2018; Accepted May 31, 2018; Published June 05, 2018

Citation: Kaur M (2018) Customer Relationship Management in Online Grocery Stores. J Bus Fin Aff 7: 339. doi: 10.4172/2167-0234.1000339

Copyright: (c) 2018 Kaur M. This is an open-access article distributed under the terms of the Creative Commons Attribution License, which permits unrestricted use, distribution, and reproduction in any medium, provided the original author and source are credited. 
However, the current business has achieved very good results and is being accelerated at a very fast pace every day. The biggest reason for this increase is consumer habits and lifestyle changes. Nowadays, the daily work of Indian consumers has become more and more busy, so there is a need to replace rather than go shopping. Therefore, online portals are such a choice.

The value of India's food and grocery industry is now 383 billion U.S. dollars, and it is expected to reach a height of 1 trillion U.S. dollars in 2020. Currently bigbasket, Nature's Basket, Grofers, Amazon Kitchen and Reliance smart are all well-known people in the good grocery business.

\section{Expected future growth of Indian grocery stores}

Despite challenges that e-retailers face, they are putting in all efforts to make online grocery retailing a success story. The retailers are trying to create a brand identity in order to drive revenue and growth in long run.

In 2016, India was considered as the fifth largest market in Asia Pacific for E-grocery on an average of US $\$ 135$ million. The leader in this race was China, Japan was ranked number second followed by South Korea. Growth of Indian online grocery market is increasing at an alarming rate. It is recognised amongst top five countries in Asia Pacific in 2016 in terms of growth (Figure 1).

\section{Models of online grocery retailing}

E-grocery is capital intensive because of the need for cold storage to keep grocery items fresh, healthy and long lasting. In online grocery presently three models are widely used namely

1. Inventory model

2. Hyperlocal model

3. Mixed model.

\section{Advantage of ordering grocery online}

- Customers can shop at any time of the day and provide 24/7 shopping services. This not only helps customers enter the shopping environment at any time, but also helps him to manage busy and busy lives. Customers can select items and make decisions at home, anywhere, anytime.
- You can choose a store collection or home delivery, which makes the service very flexible. You can make choices based on your convenience.

- You gain diversity and make sure you have a pleasant experience to win your loyalty while fulfilling your delivery store. Therefore, you can get the best variety and quality.

- Online shopping can help you get rid of shopping-related troubles, such as long queues at check-out points, finding parking spaces in shopping malls, spending time and money preparing and shopping.

- Product freshness and quality are fully guaranteed.

- You can get exciting offers when shopping online.

\section{Disadvantages of ordering grocery online}

- Some websites are poorly designed. In such websites searching for a particular item becomes a task. This can actually piss of the searcher and he/she may decide not to go online.

- Delivery charges maybe higher at peak times.

- While choosing grocery we often try to choose it personally and we try to find best amongst the choices. Anyone else choosing on your behalf doesn't go well with some people. Thus, goods may not fit in your own high standards.

- Popular offers may sell out before you get your delivery. You may be provided with a substitute, but this may sometime cause disappointment.

\section{Customer relationship management}

Theoretical framework of CRM: Customer relationship management projects often address two concepts which are almost opposite to each-other: efficiency and effectiveness. In effectiveness we see whether the company is effective in managing relationship with the customers, is it successfully maintaining its market share and is it effectively improving its market penetration and on the other hand company have to be efficient. This means the company need to make careful assessment of IT investments and projects. These both activities help in understanding whether the initiatives in conducting CRM activities are bringing in return on investment or are just a direct and clear payback.

\section{percentage of online grocery shoppers}

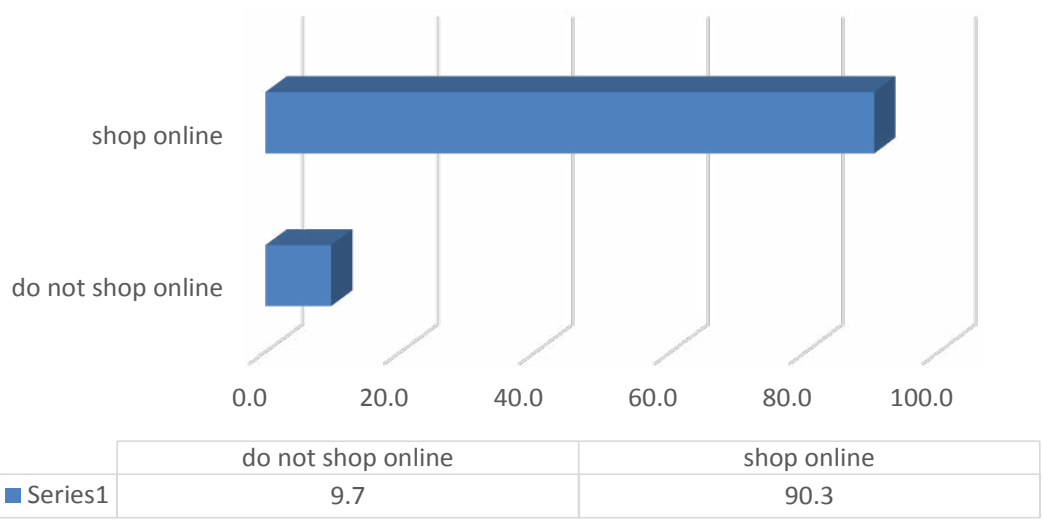

Figure 1: Percentage of online grocery shoppers. 
CRM is regarded as an important tool for "delivering revenue growth through improved customer experiences, retaining and growing existing customer bases, increasing customer acquisition rates. The vision for the CRM initiative is to enable better customer understanding, identifying the individual customer's requirements and selling them appropriate products and services. Customer relationship management is a corporate level initiative, focusing on creating and maintaining relationships with customers.

CRM Packages: There is a specialised software category that covers a set of applications designed to help businesses in managing their many business processes like

- Customer data

- Customer interaction

- Accessing business information

- Automate sales

- Track leads and contracting

- Marketing

- Customer support

- Clients and contacts

- Support vendor/ partner relationships

- Employees

- Knowledge and training

- Assets or resources

Some of well-known CRM packages in use are:

- Infusionsoft

- HubSpot CRM

- Chime

- Results CRM

- Free Agent CRM

- Base

- Prosper Works CRM

- NetSuite

- Claritysoft

- AmoCRM.

\section{Necessity of CRM in online grocery business}

1. Now customers have greater advantage due to increased awareness by use of mobile phones and internet connectivity for information sharing.

2. Now customers are more accustomed towards discounts and coupons and prefer the online portal with more such offers.

3. The quality of services provided by the online stores is gaining priority in the mind of the customers. Customer gives more consideration to portals giving good after services.

4. Also consumers have increased giving their feedback on quality, quantity and services and they expect that service providers will make use of that information in giving better shopping experience.

5. It is seen that CRM helps in better customer engagement. The more the company is involved in CRM activities, the more the customers are happy and content by the services that are provided. This further leads to customer satisfaction and loyalty.

\section{Literature Review}

Consumer attitude towards online shopping: - "Value for money"

Customers are users in the electronics market and it is very difficult to influence customers in the current highly competitive environment. Nowadays, understanding of the expectations and expectations of online stores is becoming a challenge for these online business companies. Based on the research done by Moorman et al. [1] we conclude that consumers always seek the value of their money. He will be willing to buy things from a specific online platform where he gets value for his communication. If they are well-served by the customer and provide enough value and value for return, money will not hinder the sales of the company.

A study initiated in Jaipur City found that customer' attitudes to e-marketing show that gender does not affect customers' attitudes towards online shopping and age groups. People between the ages of 18 and 30 prefer to shop online. High-income groups are major contributors to the time-saving of e-shopping. Safety and security are the main concerns of Indian consumers [2].

Grocery e-tailing: "Increase the convenience of shopping"

Constantinides stated in his research that grocery shopping is a very important part of any family's daily, weekly, or monthly purchase. The local kirana store and the local market have undergone a tremendous transformation, supermarkets and shopping centers are now turning to online retail. Reddy and Divekar mentioned that grocery retailing is difficult to start, but once it starts, it will become a loyal customer. Once customers begin to be satisfied, it is possible to repeat purchases [3].

Customer Relationship Management (CRM): An effective tool to establish a solid relationship with customers:

In the article by Dayan and Arnolds [4], they pointed out that "effective employee training" is one of the key success factors for improving CRM implementation. Employees with superior process thinking skills are preferred because they can think more thoroughly and can successfully implement CRM practices.

In recent years, CRM began to pay more attention to data mining and software development $[5,6]$. With limited face-to-face interaction online, the company will look for opportunities to implement a CRM system.

Consumers' expectations are getting higher: "The demand for smart competitive strategies"

According to Zeithaml et al. [7], customers' expectations to be "convictions regarding service delivery as a standard for accomplishing performance." Davidow and Uttal proposed that customer expectations are formed by many uncontrollable factors [8]. These factors include previous experiences with other companies, their advertisements, the psychological status of customers when providing services, customer background and value, and purchases. In addition, Zeithaml et al. pointed out that customer service expectations are based on complex 
considerations, including their own pre-purchase beliefs and others' opinions [7].

Similarly, Jalal and Bin also stated that customer expectations are related to different levels of satisfaction. It may learn from advertising and word-of-mouth communication based on previous product experiences. Santos added that before the next purchase, expectations can be seen as a pre-consume attitude; it may involve experience. The customer expectation is what the customer wants from the service. Expected diversity of definitions can lead to the conclusion that expectations are uncontrollable factors, including past experience, advertising, customers perception at the time of purchase, background, and attitude and product image.

In addition, customer expectations include pre-purchase beliefs, word-of-mouth communication, personal needs, customer experience, and other personal attitudes. Different customers have different expectations based on the customer's understanding of the product or service [9].

Click-Brick Health Alternatives "Online Grocery Shopping Reduces the Purchase of By-Products"

In a survey conducted by Nielson, the customer's intention to shop online for food and beverages increased by $44 \%$ compared with 2010 online shopping and beverage intent rate [10] - this helps us to understand that it takes a lot of time to be better understand online portals and their potential impacts and understand consumer understanding of these portals and the relevance of research in the sector. Many studies have proven that if customers buy groceries online, it will limit the purchase of malware. Because of direct exposure to bad habits, it is difficult for people to control their hunger for new foods in offline shopping. Marketing actions taken by supermarkets and food producers have enabled consumers to purchase more food $[11,12]$.

Key Characteristics of Typical Online Grocery Stores: "Points of attractions for the customer"

According to Pollan [11], the characteristics of an online grocery shopping store can be viewed as consisting of three dimensions: System quality, Information quality and Service quality. These three dimensions are also an important part of the updated model of DeLone and McLean. System quality measures the functionality of an e-commerce system. It includes "the availability, reliability, responsiveness, flexibility, integration, navigation, accessibility and timeliness of e-commerce systems" $[11,12]$. Many previous researchers have found that the availability of the system significantly affects performance and customer search strategies [13]. If the customer frequently experiences system errors or the customer's response to the customer is too slow. The customer will not be satisfied and will not trust the retailer. In addition, other aspects of system quality, such as website design and security, can also greatly affect customer trust and satisfaction Zeithaml et al. [7].

\section{Research Methodology}

\section{Research problem}

This paper investigates to figure out those attractive features in an online shopping portal that attract and satisfy customer desires and make them stick on to the same portal again in the near future and for the years to come [14].

Also, we have attempted to understand why people are getting inclined towards online shopping. Also, we need to know what part these online grocery stores are playing in attracting customers towards online shopping [15]. And what difference are they bringing in attracting customers to shop from their respective portals to gain a competitive edge.

\section{Objectives of the study}

- To study the factors considered important by the customers while choosing an online grocery store [16].

- To study customers' further expectations in the area of Customer Relationship Management by online grocery stores.

\section{Research design}

Descriptive Research Design and Exploratory Design have been used for the research. Exploratory research is used to study the existing available research work on this subject and gain insights and understanding of how online grocery stores maintains healthy relationship with customers which will help us define objective and scope of this research project [17]. Descriptive Research Design was used for collection of primary data with the help of a structured questionnaire to assess the importance of CRM in online grocery shopping.

Sampling technique: Non-probability Convenience Sampling Technique. Customers were randomly selected from local markets [18]. Hostel students, working professionals and ladies were considered while choosing the sample.

Sample size: A total of 206 customers constitute the sample needed to get an accurate understanding of customer relationship management in Online grocery stores and how it attracts and retains consumers [19].

Instrument used: The structured disguised questionnaire, for the above construct has been designed using seven variables [20,21]. Primary data were collected from a sample of 205 respondents chosen through non-probability sampling from a defined target population in the geographical spread of National Capital Region of Delhi. The respondents were between 18 and 60 years of age and consisted of $53.1 \%$ males and $48.7 \%$ females. Profession wise distribution of the respondents was: $45.7 \%$ private job, $25.9 \%$ students, $12.3 \%$ selfemployed, 9.9\% government job and 6.2\% were home-makers and retired workers [22]. Secondary data were collected from research journals, reports, white papers and cases previously published on the topic.

Tools: The collected data were converted into data matrix using SPSS 23.0 software and factor analysis was employed out the most important factors for Customer relationship management (Tables 1- 7) [23].

\section{Limitations}

The sample size is very small i.e., 206 people. This sample size cannot be used to draw inference about the population of this sample size. The study was done in a limited time-span. Thus, time becomes another constraint. The taste and preference of people will eventually change and as this study is based on their taste and preferences, thus, it cannot be used for future references.

\section{Discussion of Results}

- About $90.3 \%$ of the total respondents buy grocery online. This can be due to lack of time that people prefer to buy grocery online rather than going to the store. 
Page 5 of 7

\begin{tabular}{|c|c|c|c|c|c|}
\hline \multirow{3}{*}{ Valid } & Frequency & Percent & Valid Percent & Cumulative Percent \\
\cline { 2 - 6 } & Bonus points on referral & 38 & 18.4 & 18.4 & 126 \\
\hline \multirow{4}{*}{ Invitation to move shows/events } & 26 & 126 & 28.6 & 31.1 \\
\cline { 2 - 6 } & Periodic feedback about my satisfaction level & 59 & 28.6 & 16 & 75.7 \\
\cline { 2 - 6 } & Provision of relationship manager & 33 & 16 & 24.3 & 100 \\
\cline { 2 - 7 } & Surprise Gifts & 24.3 & 100 & \\
\hline
\end{tabular}

Table 1: Expectations of respondents in the area of CRM by online portals.

KMO and Bartlett's Test

Kaiser-Meyer-Olkin Measure of Sampling Adequacy. Bartlett's Test of Sphericity

\begin{tabular}{|c|c|} 
& 0.927 \\
\hline Approx. Chi-Square & 2810.381 \\
\hline Df & 45 \\
\hline Sig. & 0 \\
\hline
\end{tabular}

\begin{tabular}{|c|c|c|c|c|c|c|c|c|c|}
\hline \multirow[t]{2}{*}{ Component } & \multicolumn{3}{|c|}{ Initial Eigenvalues } & \multicolumn{3}{|c|}{ Extraction Sums of Squared Loadings ${ }^{a}$} & \multicolumn{3}{|c|}{ Rotation Sums of Squared Loadings } \\
\hline & Total & $\%$ of Variance & Cumulative $\%$ & Total & $\%$ of Variance & Cumulative $\%$ & Total & $\%$ of Variance & Cumulative $\%$ \\
\hline 1 & 11.989 & 63.102 & 63.102 & 11.989 & 63.102 & 63.102 & 7.915 & 41.657 & 41.657 \\
\hline 2 & 2.833 & 14.911 & 78.013 & 2.833 & 14.911 & 78.013 & 6.908 & 36.356 & 78.013 \\
\hline 3 & 0.837 & 4.405 & 82.418 & & & & & & \\
\hline 4 & 0.664 & 3.496 & 85.913 & & & & & & \\
\hline 5 & 0.45 & 2.366 & 88.28 & & & & & & \\
\hline 6 & 0.363 & 1.911 & 90.191 & & & & & & \\
\hline 7 & 0.346 & 1.82 & 92.011 & & & & & & \\
\hline 8 & 0.256 & 1.347 & 93.358 & & & & & & \\
\hline 9 & 0.216 & 1.135 & 94.493 & & & & & & \\
\hline 10 & 0.168 & 0.887 & 95.38 & & & & & & \\
\hline 11 & 0.154 & 0.809 & 96.189 & & & & & & \\
\hline 12 & 0.137 & 0.723 & 96.912 & & & & & & \\
\hline 13 & 0.133 & 0.698 & 97.61 & & & & & & \\
\hline 14 & 0.114 & 0.597 & 98.208 & & & & & & \\
\hline 15 & 0.109 & 0.574 & 98.782 & & & & & & \\
\hline 16 & 0.085 & 0.446 & 99.228 & & & & & & \\
\hline 17 & 0.06 & 0.313 & 99.542 & & & & & & \\
\hline 18 & 0.052 & 0.273 & 99.815 & & & & & & \\
\hline 19 & 0.035 & 0.185 & 100 & & & & & & \\
\hline
\end{tabular}

${ }^{a}$ Extraction Method: Principal Component Analysis.

Table 3: Total variance explained.

\begin{tabular}{|l|c|c|}
\hline \multicolumn{3}{|c|}{ Extracted Rotated Component Matrix ${ }^{\mathbf{a}, \mathbf{b}}$} \\
\hline & 1 & 2 \\
\hline Quick Response to my queries & 0.758 & \\
\hline Wide variety of grocery items & 0.897 & \\
\hline Return Options & 0.839 & \\
\hline Easy & 0.853 & \\
\hline Website/app navigation & 0.867 & \\
\hline Price & & 0.82 \\
\hline Quality & & 0.824 \\
\hline Variety of payment modes & & 0.807 \\
\hline Provision of specific item if it is not available & & 0.814 \\
\hline Free Home delivery & & 0.799 \\
\hline
\end{tabular}

aExtraction Method: Principal Component Analysis.

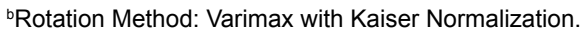

Table 4: Extracted rotated component matrix.

- It was observed that most of the online grocery shoppers shop grocery once in 2-3 months. The frequency of such customers is maximum i.e., 82 . The reason can be that people prefer nonperishable products in bulk from online grocery stores rather than buying perishable goods.

\begin{tabular}{|c|c|c|c|c|c|}
\hline & N & Range & Mean & Std. Deviation & Variance \\
\hline $\begin{array}{c}\text { Augmented } \\
\text { service factors }\end{array}$ & 206 & 5.00 & 2.9097 & 1.44405 & 2.085 \\
\hline $\begin{array}{c}\text { Core service } \\
\text { factors }\end{array}$ & 206 & 5.00 & 2.9573 & 1.57855 & 2.492 \\
\hline Valid N (listwise) & 206 & & & & \\
\hline
\end{tabular}

Table 5: Descriptive statistics.

- Further it was seen that out of the sample of 206 respondents, 50 people shop grocery once in a month, 44 customers buy grocery once in a week and 30 customers buy grocery once in 2 months.

- Most online grocery shoppers specifically $24.3 \%$ of all respondents expect periodic feedback about their satisfaction level as an initiative to Customers relationship management.

- Also, we can see that $24.3 \%$ customers expects surprise gifts, $18.4 \%$ customers expect bonus points on referral. Others initiative as per customer expectation can be invitations to movie shows and event, provision of relationship manager and bonus point on referral. 


\begin{tabular}{|c|c|c|c|c|c|}
\hline \multicolumn{5}{|c|}{ Model Summary } \\
\hline Model & $\mathbf{R}$ & $\mathbf{R}$ Square & Adjusted R Square & Std. Error of the Estimate & Sig. \\
\hline 1 & 0.676 & 0.457 & 0.456 & 0.94219 & 0.000 \\
\hline
\end{tabular}

Table 6: Regression.

\begin{tabular}{|c|c|c|}
\hline \multirow{2}{*}{$\mathrm{A}$} & Correlation & Overall satisfaction \\
\cline { 2 - 3 } & Pearson Correlation & 0.659 \\
\cline { 2 - 3 } & Sig. (2-tailed) & 0.000 \\
\hline $\begin{array}{c}\text { Augmented } \\
\text { service factors } \\
\text { core service } \\
\text { factors }\end{array}$ & Pearson Correlation & 198 \\
\cline { 2 - 3 } & Sig. (2-tailed) & 0.608 \\
\hline
\end{tabular}

Table 7: Correlation.

- We have observed that a large number of respondents i.e., 86 out of total 206 respondents were working professional who are in private jobs.

- Rest of them are from different walks of life like government jobs (11), home-makers (14), students (65), and self-employed (30).

- Out of all respondents 92 were having their monthly income in the range of $20 \mathrm{k}$ to $29 \mathrm{k}$.

- Also 34 respondents were having salary in the range of $30 \mathrm{k}$ to 39 k. 43 were having salary in range of $40-59 \mathrm{k}$.

- Only 37 people out of the sample chosen were having salary ranging above $70 \mathrm{k}$.

- After factor analysis we got two components after factor analysis namely:

Core service factors - which included

○ Price

○ Quality

○ Home delivery

○ Variety of payment modes

- Provision of specific items

- Augmented service factors- these include

- Wide variety

- Easy accessibility

-Website navigation

○ Quick response to queries

○ Return options.

- The core service and augmented service factors both were perceived important by customers as a combined mean of 2.9 and 2.95 was taken with standard variance of 1.44 and 1.57 .

- It is seen that satisfaction of customers is dependent on the core service factors and augmented service factors as the significance is less than 0.05 .

- Correlation is high between augmented and core service factors and the overall satisfaction of people with online grocery shopping with a positive Pearson correlation of 0.659 and 0.608 respectively and significance less than 0.05 .
- Consumers in future expect online grocery stores to work on areas like

1. Surprise gifts

2. Bonus points on referral

3. Provision of relationship manager

4. Invitation to movie shows/events.

\section{Conclusions and Recommendations}

\section{Objective wise conclusions}

Objective 1: To study the factors considered important by the customers while choosing an online grocery store

We studied the following factors in selection of grocery stores:

- Variety of grocery items

- Prize

- Quality

- Return options

- Easy

- App navigation

- Provision of specific items if not available

- Free home delivery.

The factors were reduced into two components after factor analysis namely:

- Core service factors- which included

$\circ$ Price

$\circ$ Quality

- Home delivery

- Variety of payment modes

○ Provision of specific items.

- Augmented service factors - these include

$\circ$ Wide variety

- Easy accessibility

- Website navigation

○ Quick response to queries

○ Return options.

Objective 2: To study customers' further expectations in the area of Customer Relationship Management by online grocery stores.

- Most online grocery shoppers specifically $24.3 \%$ of all respondents expect periodic feedback about their satisfaction level as an initiative to Customers relationship management. 
- Also, we can see that $24.3 \%$ customers expects surprise gifts, $18.4 \%$ customers expect bonus points on referral.

- Others initiative as per customer expectation can be invitations to movie shows and event, provision of relationship manager and bonus point on referral.

\section{Recommendations}

- For the grocery business to grow and prosper through online medium great importance should be given to customer requirements and expectations.

- Big Basket should focus on factors like variety of products, price, quality, return options and variety of payment modes to increase their sale and to improve their customer base

- Nature's Basket should improve their Price, website/app navigation, provision of specific items if not available, and should focus on providing better options for free home delivery to improve their competency and customer satisfaction.

- Grofers could attract more shoppers by improving their price, quality, return options and website/app navigation. These are the areas improvement in which could help grofers meet their customer expectations and desires.

- Loopholes in customer relationship management of Amazon Pantry are quality, return options, variety of payment modes and website/app navigation. If amazon pantry affords to bring excel in these areas they could beat up the competition and may be able to create value in the market.

- As per respondents reliance smart need to work on factors like wide variety of grocery items, price, variety of payment modes to increase the satisfaction of the shoppers.

- As per $18.4 \%$ respondents companies should start taking periodic feedback about the customer satisfaction level after they shop from the online grocery portal. This will increase interaction and involvement of company with the customers and will increase the level of understanding between the two. Also this will further help in improving gaps that are leading to less involvement by the customer.

- Customer now-a-days give more importance to how welcoming one company is towards the consumers. Thus companies should focus more on their relationship management behaviours

- Other measures that can be taken by the online grocery stores involve

5. Surprise gifts

6. Bonus points on referral

7. Provision of relationship manager

8. Invitation to movie shows/events.

\section{Limitations of the study and scope for further research}

- Due to constraint of time and resources the sample size of this study is limited to 206 respondents. Therefore, the inferences drawn from the study may not present the views of the entire population further studies may be conducted with bigger samples.
- This study has been conducted at a particular level of awareness about Online Grocery stores and their customer relationship management techniques, which may change over a period of time. Therefore, it is imperative that the further studies may be conducted at different levels of awareness about Customer relationship management in online grocery stores.

\section{References}

1. Moorman C, Deshpandé R, Zaltman G (1993) Factor affecting trust in market research relationships. J Mark 57: 81-101.

2. Hooda S, Aggarwal S (2012) Consumer behaviour towards e-marketing: A study of jaipur consumers. J Art Sci Commer 3: 107-118.

3. Reddy AN, Divekar R (2014) A study of challenges faced by e-commerce companies in India and methods employed to overcome them. Procedia economics and Finance.

4. Dayan O, Arnolds CA (2012) The influence of new product launching startegies on crm success: An exploratory study on management dynamics.

5. Xu M, J W (2005) Gainning customers knowledge through analytical CRM. Ind Manage Data Sys 105: 955-971.

6. Payne A, Frow P (2006) Customer Relationship Management: from Strategy to Implementation. J Mark Manage 22: 135-168.

7. ZeithamI VA, Parasuraman A, Berry LL (1988) SERVQUAL: A multi-item scale for measuring consumer perceptions of service quality. J Retailing 64: 12-40.

8. Davidow W, Uttal B (1989) Service Comapnies: Focus or Falter. Harvard Business Review.

9. Dube LB, Bechara A, Dagher A, Drewnowski A, LeBel J, et al. (2010) Obesity prevention: The role of brain and society on Individual Behavior. San Diego: Academic Press.

10. Nielson (2012) How Digital influences how we shop around the world.

11. Pollan M (2006) The Omnivore's Dilemma: A Natural History of Four Meals.

12. Popkin BM (2002) An overview on the Nutrition Transition and its Health Implications: The Bellagio Meeting. Public Health Nutr 5: 93-103.

13. Crosby LA, Evans KR, Cowles D (1990) Relationship quality in services selling An Interpersonal influence perspective. J Mark 54: 68-91.

14. Kolesar M, Galbraith RW (2000) A service-marketing perspective on e-retailing implications of e-retailers and directions for further Research. Internet Research 10: 424-438.

15. Levy M (1998) Retailing Management. Irwin.

16. Wirtz J, Lovelock C (2011) Service Marketing-People, Technology, Strategy (8th edn.), Prentice:New Jersey.

17. Palmatier RW, Dant RP, Grewal D, Evans KR (2006) Factors influencing the effectiveness of relationship marketing: A meta-analysis. J Mark 70: 136-153.

18. Parasuraman A, ZeithamI VA, Berry LL (1985) A conceptual model of service quality and its implications for future research. J Mark 49: 41-50.

19. Van den Poel D, Leunis J (1996) Perceived risk and risk reduction strategies in mail order versus reatil store buying. The international review of retail, Distribution and Consumer Research 13: 351-371.

20. Rempel JK, Holmes JG, Zanna MP (1985) Trust in close relationships. J Personal Soc Psychol 49: 95-112.

21. Slyke C, Belanger F, Comunale C (2004) Factor influencing the adoption of web-based shopping: The impact of trust. Database for Advances in Information Systems 35: 32-49.

22. Boulding W, Staelin WJ, Ehret M, Johnston WJ (2005) A Customer Relationship Management Roadmap: What is known, Potential Pitfalls, and where to go. $J$ Mark 69: 155-166.

23. Wang YD, Emurian $\mathrm{HH}$ (2005) Trust in E-commerce:Considerations of interface design factors. Journal of E-commerce in Organizations 3: 42-60. 